\title{
A internalização dos tratados sobre Direitos Humanos na ordem jurídica brasileira e a problemática da ordem internacional*
}

\section{The internalisation of Human Rights treaties in the brazilian legal system and the problem of international order}

Dalliana Vilar Lopes Gills Vilar Lopes ${ }^{2}$
Recebido em: 30/09/2015.

Aprovado em: 07/04/2016.

1 Especialista em Direito e Processo do Trabalho (Escola da Magistratura do Trabalho da 10a Região / Faculdade Processus). Bacharela em Direito pela Universidade Federal da Paraíba (UFPB). Analista Judiciário (Área Judiciária) e Assistente de Ministro no Tribunal Superior do Trabalho (TST). E-mail: dalliana.vilar@gmail.com.

2 Mestre e Doutorando em Ciência Política pela Universidade Federal de Pernambuco (UFPE). Bacharel em Relações Internacionais pela Universidade Estadual da Paraíba (UEPB). Specialized Course pela National Defense University (NDU). Bolsista do Pró-Estratégia (CAPES/SAE). E-mail: gills@ gills.com.br.

\section{Resumo}

Este trabalho tem como objetivo relacionar preceitos das Relações Internacionais com os do Direito Internacional Público, especificamente quanto à problemática da incorporação/internalização de tratados internacionais sobre Direitos Humanos no ordenamento jurídico brasileiro. Justifica-se tal estudo pelo fato de existir divergência entre correntes de pensadores quando o assunto é a supremacia da ordem nacional frente à internacional e vice-versa. Para atingir seu fim, este artigo se utiliza de teóricos da Escola Inglesa de Relações Internacionais e de doutrinadores do Direito Internacional Público - com ênfase no denominado Direito Constitucional Internacional -, pautando-se na análise qualitativa, em que pese a análise de documentos jurídicos. Conclui-se que, apesar das divergências doutrinárias sobre qual sistema de incorporação dos tratados de direitos humanos - legislativa ou automática - deve ser aplicada ao caso brasileiro, a coexistência harmônica entre ambos garante ainda mais a efetivação de tais tratados.

Palavras-chave: Brasil. Direitos humanos. Direito internacional público. Relações internacionais.

\begin{abstract}
This work aims to relate precepts of International Relations to Public International Law, specifically about the problems surrounding the incorporation / internalization of international Human Rights treaties in Brazilian legal system. Such a study is justified in the fact that there is much disagreement among current thinkers when the issue is the supremacy of national over international order and vice versa. In order to achieve the main objective, this article uses the theoretical English School of International Relations and scholars of Public International Law - with particular emphasis on International Constitutional Law - based on the qualitative analysis, notwithstanding the analysis of legal documents. It concludes that, despite doctrinal differences about which system of human rights treaties incorporation - if legislative or automatic - should be applied to the Brazilian case, the harmonic coexistence of both ensures the effectiveness of such treaties even more.
\end{abstract}

Keywords: Brazil. Human rights. International Public Law. International Relations. 


\section{Introdução}

Como aponta Homem (2010, p. 314), a expressão "Direito Internacional" é mencionada pela primeira vez por Jeremy Bentham (1748-1832), o pai do utilitarismo (ARAUJO, 2000), justamente para substituir a noção de "direito das gentes" 3 associada ao jusnaturalismo. Nesse viés, "Direito Internacional" se torna um conceito moderno para designar o fato de que Estados possuem direitos ex post - e não ex-ante - suas fundações/constituições, ou seja, tais direitos são positivados, adquiridos, e não apenas naturalmente preexistentes. Em todo caso, juristas como Rezek (2013, p. 25) utilizam os dois termos como sinônimos.

Seja "direito das gentes", seja "Direito Internacional", o certo é que, para a doutrina brasileira, existem duas ordens jurídicas, ou, ao menos, duas facetas de uma mesma ordem, quais sejam: a nacional e a internacional.

Para decifrar o diálogo que há entre elas, propomos, aqui, um estudo acerca do modus operandi brasileiro na internalização de tratados internacionais.

Nesse sentido, o presente artigo, pautando-se pelo método qualitativo - em que pese a análise doutrinária e a revisão bibliográfica de documentos jurídicos nacionais e internacionais -, busca compreender, à luz de teóricos da Escola Inglesa de Relações Internacionais e do Direito Internacional Público, como o Brasil incorpora os tratados internacionais, com ênfase nos de Direitos Humanos.

\section{Da problemática da ordem internacional e dos tratados internacionais}

Teóricos da Escola Inglesa de Relações Internacionais entendem que o Direito Internacional é uma das instituições efetivas - ao lado de outras, como a diplomacia, o equilíbrio de poder e a guerra - da sociedade internacional.

Por exemplo, Bull (2002, p. 147) conceitua Direito Internacional como o conjunto de regras que vinculam os agentes da política mundial, no que tange a suas mútuas relações; por meio dele, a elas se confere status legal. Por sua vez, Wight (2002, p. 92) atesta que até o início da década de 1920, com a criação da Sociedade/Liga “[...]

Kant (2008, p. 30) entende que "a ideia do direito das gentes pressupõe a separação de muitos Estados vizinhos, entre si independentes $[\ldots]$.." das Nações, o Direito Internacional não tinha alternativa senão aceitar a guerra como um relacionamento legítimo entre os estados, independentemente do fato de a causa ser ou não justa"; mas, mesmo assim, o Direito Internacional "não a declarou ilegal", i.e., não impediu juridicamente a ocorrência de conflitos internacionais.

Nesse prisma, Bull (2002, p. 47) concebe a sociedade internacional como um grupo de Estados que, conscientes de certos valores e interesses comuns, estão ligados por um conjunto de regras partilhadas, participando, assim, de organismos e mecanismos em comum. Em que pese essa mesma sociedade internacional anárquica, devido à falta de um ente legislador supranacional -, em sua roupagem hodierna, ser definida e delimitada também por laços de comunhão entre pessoas, e não apenas entre Estados, percebe-se que ela reclama uma disciplina normativa, no intuito de se dotar de certa ordem.

Seguindo esse viés da Escola Inglesa, para se entender o sistema internacional ${ }^{4}$ atual, faz-se necessário apenas um mínimo de interdependência entre os atores internacionais, sendo eles estatais ou não $0^{5}$. Assim, tal conceito passa a ser delimitado pela dita "ordem internacional"', voltada, na percepção do precitado estudioso australiano, para a garantia da vida - ou, em outras palavras, para a proteção contra a violência - e da propriedade, bem como do cumprimento dos acordos (BULL, 2002, p. 47), de forma tal a preservar a própria sociedade internacional, com a respectiva manutenção da soberania estatal e da paz mundial.

Desse modo, uma vez calcada na soberania dos Estados e no princípio da cooperação internacional, a sociedade de Estados ou sociedade internacional se torna uma expressão de coordenação - e não de subordinação - de interesses (REZEK, 2013, p. 24). Nesse sentido, tal sociedade é ampliada pelo progressivo aprofundamento

4 Para Bull (2002, p. 15), um sistema internacional se constitui quando "[...] dois ou mais estados têm suficiente contato entre si, com suficiente impacto recíproco nas suas decisões, de tal forma que se conduzam [...] como partes de um todo". Já o conceito de sociedade internacional está vinculado a um grau maior e mais institucionalizado de reciprocidade legal.

5 Não à toa que Watson $(2004$, p. 71$)$, utilizando-se dos ensinamentos da Escola Inglesa, afirma que o sistema grego-pérsico serviu de base ao europeu moderno porque aquele ensejava relações interdependentes entre as poleis.

6 Há de se rememorar que o subtítulo da obra-mor de Bull (2002, grifo nosso) é "um estudo da ordem na política mundial". 
do processo de globalização e passa a apresentar como um de seus princípios a celebração de tratados internacionais, em suas múltiplas espécies.

Os tratados internacionais, nesse ínterim, com fundamento na Convenção de Viena sobre o Direito dos Tratados, de 1969, bem como na Convenção de Viena sobre o Direito dos Tratados entre Estados e Organizações Internacionais (OIs) ou entre OIs, de 1986 ${ }^{7}$, compreendem: Acordos escritos, firmados por Estados e organizações internacionais dentro dos parâmetros estabelecidos pelo Direito Internacional Público, com o objetivo de produzir efeitos jurídicos no tocante a temas de interesse comum. (PORTELA, 2010, p. 83).

De tal modo, os tratados se caracterizam pela convergência de vontades dos atores competentes, pelo que apenas são vinculantes, a priori, com a anuência desses sujeitos, adotando a forma escrita, haja vista serem atos solenes, formais.

A partir dessas características, consigna-se o dever de, em sua elaboração, os tratados internacionais obedecerem a procedimentos e exigências formais estabelecidos na prática internacional (PORTELA, 2010, p. 84-85), em decorrência de outros tratados ou do costume internacional ou, ainda, de ambos, todos eles considerados fontes do Direito Internacional Público ${ }^{8}$ (REZEK, 2013, p. 33).

Os tratados, não sendo meras declarações de cunho político nem marcados pela discricionariedade, criam direitos e obrigações na seara internacional e passam a vincular as partes acordantes, tanto em acordos bilaterais ou quanto em multilaterais, não apenas no âmbito internacional, mas também no âmbito doméstico ou interno. De tal sorte, tais obrigações, assumidas internacionalmente, mantêm uma comunicação com o direito

De acordo com a ONU (2014), a Convenção de 1986 ainda não atingiu o número mínimo de ratificações para poder entrar plenamente em vigor. É interessante notar que o Brasil a assinou na data de criação, mas ainda não a ratificou (ONU, 2014; REZEK, 2013, p. 38).

8 Além dessas duas Convenções, há a ainda vigente Convenção de Havana sobre Tratados, de 1928. Ademais, como lembra Rezek (2013, p. 33), o art. 38 do Estatuto da Corte de Haia ou Tribunal Internacional de Justiça -, no âmbito das Nações Unidas, elenca, além dos tratados, duas outras fontes do Direito Internacional Público, a saber: costumes internacionais e princípios gerais do Direito. Além destas, existem ainda outras fontes, como: os atos unilaterais dos Estados e "as decisões tomadas no âmbito das organizações internacionais" (REZEK, 2013, p. 33). interno, em face do qual aquelas passam a valer, em regra, tão somente após sua incorporação ou internalização.

Essa internalização se põe como um processo por meio do qual os tratados internacionais passam a compor a ordem jurídica interna dos entes estatais, adquirindo, dessa forma, status semelhante às demais espécies normativas que integram a ordem nacional. Nesse passo, Dinh, Pellet e Dailler (apud PORTELA, 2010, p. 121) destacam a função sócio-jurídica de tal processo, dispondo que:

Com isso, a aplicação dos preceitos do Direito das Gentes passa a contar com o aporte direto do poder soberano do Estado que, por meio de órgãos como o Judiciário, pode impor a observância das normas internacionais como se internas fossem. Com a incorporação, os tratados podem ser invocados por qualquer pessoa natural ou jurídica dentro do território de um ente estatal e podem orientar e fundamentar as ações e decisões dos órgãos e autoridades nacionais dos poderes Executivo, Legislativo e Judiciário. A internalização é, em suma, o que possibilita que as normas internacionais se imponham ao governo, às autoridades e aos nacionais do Estado.

Assim, evidencia-se a importância dessa temática para o Direito Internacional Público: a incorporação dos tratados ao ordenamento interno do Estado soberano. Tal meandro adquire ainda mais relevância quando se trata dos tratados internacionais sobre Direitos Humanos, seja em virtude da imprescindibilidade da eficácia social desses direitos na sociedade internacional e na ambiência interna dos Estados, seja em face das peculiaridades que envolvem tal incorporação em sede jurisprudencial em decorrência das inovações trazidas pela Emenda Constitucional n. 45, de 2004 (EC 45/2004) ${ }^{9}$.

No $₫ 3^{\circ}$ do art. $5^{\circ}$ da Constituição Federal brasileira de 1988, a EC 45/2004 equiparou os tratados e convenções internacionais sobre Direitos Humanos ao status de Emendas Constitucionais que forem aprovados, em cada Casa do Congresso Nacional, em dois turnos, por $3 / 5$ dos votos dos respectivos membros (BRASIL, 1988) ${ }^{10}$. Esse tratamento especial a matérias de Direitos Humanos tem

9 Grosso modo, tal Emenda, em seu mister de reformar o Judiciário brasileiro, carrega consigo um sentimento de busca por celeridade processual e efetividade da prestação jurisdicional.

10 Nesse sentido, até a presente data, apenas a Convenção Internacional sobre os Direitos das Pessoas com Deficiência e seu Protocolo Facultativo, assinados em Nova York, em 2007, foram aprovados nos termos do referido dispositivo e, por conseguinte, emendados à Constituição (BRASIL, 1988). 
dado azo a discussões doutrinárias e jurisprudenciais, desde então, ao lado da regra disposta no $\$ 1^{\circ}$ do art. $5^{\circ}$, que dota as normas que definem direitos e/ou garantias fundamentais de eficácia imediata ${ }^{11}$.

Tudo o que sobredito se firma como objeto do presente trabalho, em que se busca, em apertada síntese, apresentar o disciplinamento dos tratados internacionais sobre Direitos Humanos, com especial atenção ao seu processo de incorporação à luz dos ditames constitucionais, à luz de que Piovesan (2007), dentre outros autores, defende a existência de um novo ramo do saber jurídico, qual seja, o Direito Constitucional Internacional.

\section{Dos tratados sobre Direitos Humanos no Bra- sil à luz do Direito Constitucional Internacio- nal}

Os Direitos Humanos emergem na seara jurídica como um conjunto de faculdades e instituições pautadas na concretização da dignidade, da liberdade e da igualdade humanas, e, em cada momento histórico, revestem-se de um caráter específico (PIOVESAN, 2007, p. 3). Assim é que, em sua perspectiva, tal qual dispõe Bobbio (2004, p. 9-10), os direitos fundamentais se expressam nas seguintes gerações ou dimensões:

$1^{\text {a }}$ geração/dimensão: direitos civis ou políticos;

2a geração/dimensão: direitos sociais; e

$3^{\text {a }}$ geração/dimensão: direitos de titularidade difusa ou coletiva.

Muito debatida e questionada na doutrina, a sobredita classificação cede espaço para a compreensão de que os direitos humanos se postam como interdependentes, interrelacionados e indivisíveis (ALVES, 2001, p. 109-110), como estabelece expressamente a Declaração e o Programa de Ação de Viena sobre Direitos Humanos, de 1993. No particular, esta reafirma, respectivamente em seus itens I.5 e I.32, o fato de que " $\mathrm{t}$ ] odos os Direitos do homem são universais, indivisíveis, interdependentes e inter-relacionados", bem como “[...]a importância de garantir a universalidade, a objetividade e a não seleção na ponderação de questões relacionadas com os Direitos do homem" (ONU, 1993).

11 Como lembram Mendes e Branco (2014, p. 155), "as normas do art. $5^{\circ}$ tendem a apresentar alta densidade normativa, inserindo-se no grupo das normas de eficácia plena ou contida”.
Em seu mister, tais direitos estruturam a base do Estado Democrático de Direito ${ }^{12}$, positivando reivindicações morais e políticas reconhecidas como direito, i.e., como conquistas que se concretizam tanto no âmbito da sociedade internacional quanto no do direito interno, especialmente a partir da incorporação do que se pode chamar de "leis internacionais", ou seja, dos tratados ou convenções internacionais.

Assim, a efetiva incorporação desses instrumentos jurídicos no plano nacional é de fulcral importância para que seus propósitos sejam alcançados, obrigando os Estados a melhorar as condições dos indivíduos (PIOVESAN, 2007, p. 4) e, acrescente-se, das coletividades, garantindo-lhes tais direitos fundamentais. Esses direitos refletem, assim, a aceitação geral de que todo indivíduo - não apenas os nacionais em um Estado, mas também os estrangeiros em seu território - deve ter direitos a serem respeitados e tutelados por todos os Estados. Logo, sua observância não é apenas um assunto de jurisdição doméstica, mas também de interesse internacional, que, como tal, é regulado pelo Direito Internacional.

Todo esse estado de coisas remete, por consequência, à internacionalização, idiossincrasia do Direito Internacional. Esse traço implica, nas palavras de Tavares (2009, p. 521), "uma retomada da clássica reivindicação de seu caráter universal e supra-estatal [sic]" a desaguar na sua universalidade, de modo a se destinar a influenciar a atuação dos poderes constituintes, sendo mais do que máximas filosóficas, teóricas e abstratas (TAVARES, 2009 , p. 521), para se tornarem normas cogentes, vinculantes e dotadas de eficácia jurídica.

Há de se falar, até mesmo, que os direitos previstos nas declarações são partes integrantes da Constituição Federal de 1988, em face do disposto no $\$ 2^{\circ}$ do art. $5^{\circ}$ da Lei Fundamental brasileira. O que se irradia também em outros Estados, como Áustria e Peru, os quais, tal qual destaca Tavares (2009, p. 521),

[...] chegaram ao ponto máximo de relação com os direitos humanos, pois constitucionalizaram diretamente os textos internacionais sobre direitos humanos no lugar do seu catálogo de direitos fundamentais ou ao seu lado". Também, ainda, como se dá em outros Estados, em que a

12 De acordo com Zaverucha (2005, p. 31, grifo do autor), "Governo da Lei (rule of law) ou Estado de Direito é um tipo ideal no sentido de que todos os indivíduos são tratados igualmente. [...]Surge o governo pela lei (rule by law)[,] em vez do governo da lei". 
interpretação dos seus direitos é feita à luz das declarações universais.

Desse modo, tal internalização jurídica acaba por traduzir a imprescindibilidade de se impor limites à percepção tradicional de soberania estatal, fundada apenas na noção de hard power, para responsabilizar o "Estado na arena internacional, quando as instituições nacionais se mostrem omissas ou falhas na tarefa de proteger os direitos humanos internacionalmente assegurados" (PIOVESAN, 2007, p. 8). Paralelamente a isso, os tratados internacionais emergem como medidas adicionais, complementando as determinações nacionais no que tange a esses direitos básicos ou mínimos, de forma a não substituírem as leis e instituições nacionais, mas, sim, de lhes adicionar melhor proteção.

Esse fenômeno, na realidade brasileira, traduz-se no alargamento dos direitos e garantias fundamentais positivados no Texto Constitucional, o qual congrega todas as diferentes gerações/dimensões de Direitos Humanos acima elencadas. Direito material positivado este que estava, no que se refere à sua efetividade na ordem interna, em verdadeiro descompasso com as obrigações assumidas internacionalmente pelo Estado brasileiro. Procurou-se, é bem verdade, corrigir essa situação com o advento da EC 45/2004, a qual estabeleceu um novo procedimento de incorporação dos tratados sobre Direitos Humanos no Brasil.

O novo modus operandi, uma vez devidamente obedecido, implicaria na internalização de tais direitos com status de Emenda à Constituição e, portanto, é capaz de derrogar ou revogar lei infraconstitucional em sentido contrário, bem como o próprio texto constitucional.

Por conseguinte, essa reforma vem para extirpar a celeuma doutrinária a respeito do status dos referidos tratados. Uma vez internalizados pelo procedimento disposto no $₫ 3^{\circ}$ do art. $5^{\circ}$, possuem status constitucional. Antes, para alguns, eles eram absorvidos como normas constitucionais e, para outros - acompanhados pelo Supremo Tribunal Federal (STF), em um determinado momento -, estavam no mesmo patamar hierárquico da legislação ordinária (TAVARES, 2009, p. 521).

Superada a primeira celeuma, com a norma do $\$$ $3^{\circ}$ do art. $5^{\circ}$ da Carta Política brasileira, em um segundo momento, o STF, refletindo sobre o Pacto Internacional de Direitos Civis e Políticos, de 1966, e o Pacto de San José da Costa Rica, de 1969, fixa tese no sentido de que os tratados internacionais sobre Direitos Humanos apro- vados por procedimento diverso do estabelecido pela EC 45/2004 possuem status supra legal, ou seja, estão acima da lei e abaixo da Constituição ${ }^{13}$. Assim, constrói-se uma nova categoria na seara da hierarquia das normas, a qual predomina em seu posicionamento atual e cujo modus operandi incorporativo é visto na próxima seção.

\section{A internalização dos tratados sobre Direitos Humanos na ordem jurídica brasileira}

Expõe-se o que a Constituição Federal de 1988 afirma acerca da celebração de tratados:

Art. 49. É da competência exclusiva do Congresso Nacional: I - resolver definitivamente sobre tratados, acordos ou atos internacionais que acarretem encargos ou compromissos gravosos ao patrimônio nacional [...]

Art. 84. Compete privativamente ao Presidente da República: [...]VII - manter relações com Estados estrangeiros e acreditar seus representantes diplomáticos. VIII - celebrar tratados, convenções e atos internacionais, sujeitos a referendo do Congresso Nacional. (BRASIL, 1988).

Como se observa, os artigos 49 e 84 da Carta Maior do Brasil versam sobre as competências de celebração de tratados do Corpo Legislativo e do Chefe do Executivo brasileiros, respectivamente. Isso quer dizer que, na prática - e terminada a fase de negociações -, o Presidente da República "[...] está livre para dar curso, ou não, ao processo determinante do consentimento" (MAZZUOLI, 2001, p. 88). Caso esteja satisfeito com o tratado assinado, ele o remete à apreciação do Legislativo, o qual, por seu turno e revestido pela soberania nacional a que se refere $\mathrm{o}$ art. $1^{\circ} \mathrm{da}$ Carta, poderá prosseguir com a conclusão de tal tratado.

A Convenção de Viena sobre o Direito dos Tratados, editada em 1969, positiva normas de direito consuetudinário consolidadas no âmbito internacional, motivo pelo qual se defende sua aplicação, inclusive, aos Estados que dela não fazem parte. Posteriormente, em 1986, a Convenção de Viena sobre o Direito dos Tratados entre Estados $e$ OIs ou entre OIs é posta a assinaturas. O engendramento de ambas as Convenções pode ser encarado diante do relevante papel desempenhado pelos tratados na história

13 Vide os Recursos Extraordinários n. 349.703 e 466.343, bem como o Habeas Corpus n. 87.585, leading cases sobre a tese em tela. 
das relações internacionais (HOMEM, 2010), bem como sua configuração enquanto fonte do Direito Internacional (REZEK, 2013, p. 33) e meio de resolução pacífica das controvérsias, pautado pelo princípio do pacta sunt servanda ${ }^{14}$, da cooperação e da boa-fé internacionais e com fulcro nas obrigações assumidas perante o Sistema das Nações Unidas.

A Convenção da década de 1960 é restrita às relações interestatais, como expressão da prevalência do pensamento realista no âmbito das relações internacionais e do Direito Internacional. Já a da década de 1980, mais abrangente, a incluir as OIs como sujeitos de Direito Internacional - e, portanto, se aproximar de uma ótica mais neoinstitucionalista liberal -, estabelece uma série de rigorosas formalidades atinentes ao processo de formação dos tratados internacionais.

Nesse viés, como dispõe Mazzuoli (2001, p. 4265), baseado nos instrumentos normativos precitados, quatro são as fases solenes pelas quais os tratados têm de passar até sua conclusão, no Brasil, a saber: (i) negociações preliminares; (ii) assinatura ou adoção pelo Poder Executivo; (iii) aprovação parlamentar, ou referendum; e (iv) ratificação ao texto convencional ou adesão deste. Ao que se soma, a promulgação mediante Decreto do Presidente da República e a publicação no Diário Oficial da União (DOU), os quais visam a dotar o tratado incorporado de aplicabilidade e executoriedade internas, complementando ou aperfeiçoando seu processo de formação.

Não obstante o processo acima delineado, a Lei Maior de 1988 veio a estabelecer uma normatização peculiar para a incorporação dos tratados internacionais sobre Direitos Humanos na ordenança jurídica brasileira. Assim determinou-a nos $\$ \$ 1^{\circ}, 2^{\circ}$ e $3^{\circ}$ do art. $5^{\circ}$, o qual trata dos direitos e garantias fundamentais. A priori, positivou a aplicabilidade imediata das normas definidoras de tais direitos e garantias e, a posteriori, os afixou expressamente no rol constitucional como numerus apertus, ou seja, não taxativo, para, finalmente com a EC 45/2004, estender o status constitucional aos tratados sobre Direitos Humanos aprovados na forma já descrita.

No caso desses tratados, não há que se falar em intermediação pelo Poder Legislativo para validar o ato com força de lei, outorgando-lhe vigência e obrigatorie-

14 É o “[...] princípio segundo o qual o que foi pactuado deve ser cumprido - é um modelo de forma fundada no consentimento perceptivo" (REZEK, 2013, p. 25). dade (PIOVESAN, 2007, p. 82). Isso se deve porque os direitos que integram tal tratado internacional, na forma dos $\$ \$ 1^{\circ}$ e $2^{\circ}$ do art. $5^{\circ}$, passam a integrar o elenco dos direitos constitucionalmente consagrados e direta e imediatamente exigíveis no plano da ordem interna. Assim, não há mais que se sustentar a tese dualista ${ }^{15}$ de que os tratados obrigam diretamente os Estados, mas não geram direitos subjetivos para os particulares, restando uma dependência dessa intermediação legislativa (PIOVESAN, 2007, p. 82), ou seja, uma situação similar à hipótese da dita norma constitucional de eficácia limitada no âmbito do direito interno brasileiro.

Essa evolução implica relevantes consequências para o plano jurídico interno, uma vez que se permite que os particulares procedam à exigência de inovação direta dos direitos e liberdades que se lhes asseguram, bem como estabelece a proibição de condutas violadoras a tais direitos, podendo até mesmo as invalidar.

Assim, pela entrada em vigor desses tratados, toda norma preexistente de menor hierarquia que com eles seja incompatível perde automaticamente sua força por causa do efeito negativo que detêm. Além disso, é por tal razão que qualquer decisão contrária aos tratados passa a ser recorrível, e tanto o tribunal nacional quanto o internacional competentes podem declarar a antijuridicidade/ ilicitude da conduta contrária ao tratado (PIOVESAN, 2007, p. 82).

Dessa forma, o direito brasileiro adota um sistema misto de incorporação dos tratados. De tal sorte que, aos tratados internacionais de Direitos Humanos, aplica-se a sistemática de incorporação automática - tratados self-executing -, pela qual eles se incorporam de imediato ao direito nacional em virtude do ato de ratificação. Sendo assim, eles são dotados de uma maior celeridade na absorção pela ordenança interna, em consonância com o princípio da dignidade da pessoa humana, que abrange não apenas a concretização dos direitos fundamentais, mas outrossim sua célere efetividade. Ao passo que aos demais tratados - os que abarcam matéria ordinária, tratados not self-executing - aplica-se a sistemática da incorporação legislativa, pela qual os enunciados dos tratados ratificados não são incorporados prontamente pelo direito nacional, mas dependem, necessariamente, de legislação que os implemente.

15 Vide definição mais adiante. 
Nesse ponto, é preciso frisar que existem duas correntes quanto ao grau de independência do direito interno em relação ao internacional.

A primeira delas é a monista, que apregoa o diálogo entre as normas das esferas nacional e internacional. Essa corrente pode ser subdividida em duas alas, a saber: a nacionalista, mais ligada à soberania estatal - para a qual o ápice da pirâmide normativa é a Constituição -, que faculta a incorporação ou não de uma norma internacional; e a internacionalista - cujo expoente-mor é o alemão Hans Kelsen -, a qual, por sua vez, defende que os ordenamentos jurídicos dos países devem se ajustar ao ordenamento internacional (REZEK, 2013, p. 26-27), quando uma norma internacional estiver conflitando com uma nacional.

Em sentido contrário à corrente monista estão os adeptos do dualismo, os quais veem os direitos interno e internacional como esferas totalmente independentes uma da outra, quer dizer, sem nenhum tipo de subordinação. Para essa visão, um tratado internacional só é válido no território de um Estado se ele passar pelo crivo dos seus Poderes autônomos, ou seja, deve haver uma espécie de devido processo legal de incorporação/ internalização do tratado. Essa corrente, assim como a primeira, também se subdivide em duas vertentes, quais sejam: a extremada, que defende que o tratado internacional só terá vida legal em um país se for transformado em lei nacional; e a mitigada ou moderada, que apregoa que o tratado - uma vez em conformidade com a legislação nacional - precisa apenas ser decretado como lei pelo Chefe do Executivo.

O Esquema 1 demonstra tais concepções, a fim de que a posição brasileira possa ser melhor alocada no quadro onto-epistemológico supramencionado.

\section{Esquema 1 - Correntes jurídicas quanto à incorporação doe tratados}

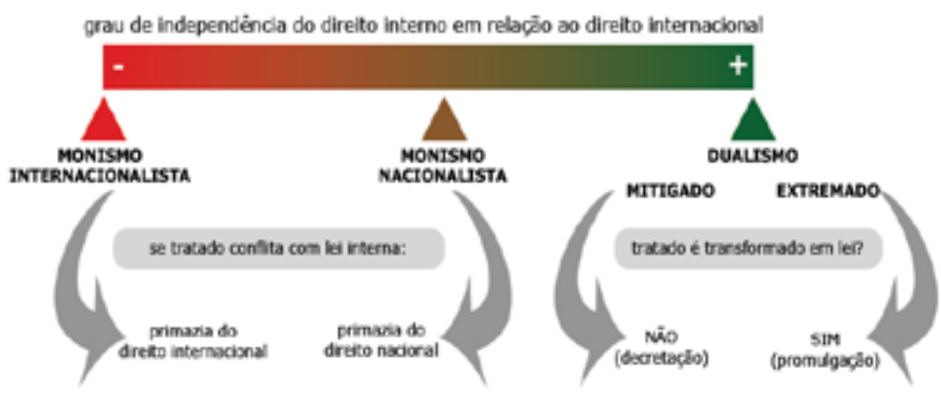

Fonte: Elaboração própria

Em consonância com essas considerações, pode-se afirmar que o sistema brasileiro adota a perspectiva do "dualismo mitigado"16 (MELLO, 1998). Por um lado, diante da incorporação automática, fala-se da concepção monista, a qual entende o direito internacional e o interno em plena simbiose, como uma ordem jurídica uma. Por outro, ante à sistemática legislativa - não-automática -, fala-se em dualismo, segundo o qual tais ordens jurídicas são independentes e autônomas, não apresentando contato nem qualquer interferência entre si, já que, para que tais tratados apresentem cogência interna, passa a ser imprescindível a expedição de decreto de execução pelo Presidente da República. Isso, ao revés, não se dá com os anteriores, em virtude do positivado no $₫ 1^{\circ}$ do art. $5^{\circ}$ da Constituição Federal de 1988. É nesse mesmo sentido que Celso de Mello, Ministro da Suprema Corte brasileira, afirma que:

[...] impende destacar que o tema concernente à definição do momento a partir do qual as normas internacionais tornam-se vinculantes no plano interno excede, em nosso sistema jurídico, à mera discussão acadêmica em torno dos princípios que regem o monismo e o dualismo, pois cabe à Constituição da República - e a esta, somente - disciplinar a questão pertinente à vigência doméstica dos tratados internacionais. (MELLO, 1998, grifo nosso).

Nesse passo, alude Tavares (2009) que o fundamento de tamanha distinção se encontra na natureza de cada um dos tratados: aqueles de natureza usual ou ordinária abarcam meros compromissos recíprocos, marcados pela disponibilidade e, muitas vezes, pelo caráter comercial, o que não se dá com os tratados sobre Direitos Humanos, os quais não procuram resguardar meras prerrogativas estatais, mas, sim, assegurar o mínimo de direitos inerentes à pessoa humana, razão por que não podem ser tidos como disponíveis.

Apesar disso, Mello (1998) possui entendimento distinto quanto à incorporação automática dos tratados sobre Direitos Humanos. Ele afirma que tal processo não ocorre, embora ressalte ser plausível esse entendimento defendido por alguns. Assim, aduz que, em verdade, o $₫$ $3^{\circ}$ do art. $5^{\circ}$ da Constituição Federal impõe às duas Casas do Congresso brasileiro a tramitação do tratado sobre Direitos Humanos nos mesmos moldes das Emendas

16 Embora o monismo nacionalista seja uma ideia que "[... norteia as convicções judiciárias em inúmeros países do ocidente - incluídos o Brasil [...] -, quando os tribunais enfrentam o problema do conflito entre normas de direito internacional e de direito interno" (REZEK, 2013, p. 27, grifo nosso). 
Constitucionais, com processo qualificado de aprovação, como já mencionado, envolvendo, inclusive, a desnecessidade de sanção presidencial, por exemplo, de modo a não ter o Legislativo discricionariedade na forma de processamento desses tratados. Logo, a não aprovação pelo Congresso descaracteriza sua hierarquia constitucional e impede que o Estado brasileiro o internalize como norma (TAVARES, 2009, p. 528-530).

\section{Considerações finais}

Pelas observações esposadas supra, resta evidente a atual configuração da sociedade internacional, pautada, em face das Convenções de Viena sobre os Tratados, de 1969 e de 1986, pelo inter-relacionamento entre entidades estatais e OIs, em que emerge a dita ordem internacional. Esta, por sua vez, é marcada pela emergência de inúmeros instrumentos normativos de tutela dos Direitos Humanos, como consectário lógico da consolidação do Direito Internacional dos Direitos Humanos, a delimitar os contornos do universalismo do Sistema das Nações Unidas.

Em evidência à questão do relacionamento entre a ordem internacional e a ordem interna, exsurge o clássico debate monismo-dualismo e, como seu corolário, a definição de qual sistemática se adota no Brasil, se a da incorporação legislativa, ou se a da incorporação automática.

Toda a análise emerge com o fito de desaguar na celeuma doutrinária já descrita, em que, para alguns, em verdade, não há que se falar em automatismo, mas apenas em um novo procedimento de incorporação dos tratados sobre Direitos Humanos, como sustenta Tavares (2009). Nesse caso, deve-se necessariamente remontar ao $\$ 3^{\circ}$ do art. $5^{\circ}$ da Lei Fundamental brasileira, o qual estipula procedimento legal similar ao adotado para aprovação das Emendas Constitucionais, a vincular o Poder Legislativo a tal forma que as normas internalizadas passem a ter status constitucional.

A concepção da mútua harmonia entre os dois procedimentos está muito mais consentânea com o Direito Internacional dos Direitos Humanos, para cuja concretização as ordenanças internacional e interna devem convergir no sentido de dar maior efetividade a esses direitos, os quais não foram dados, mas, sim, conquistados no decorrer do processo histórico moderno. Assim o é à vista do universalismo que norteia o Sistema das Nações Unidas e com o qual é adequada a mitigação da soberania estatal em seus moldes tradicionais, em prol da adoção automática dos tratados internacionais sobre Direitos Humanos.

Por essas razões, deve-se pensar o processo legislativo de incorporação desses tratados - e, pois, normas fundamentais - não como um fim em si mesmo, mas como um meio para se alcançar a real concretização dos direitos fundamentais, percebidos como inter-relacionados e indivisíveis. É nesse sentido que a Constituição Federal brasileira consagra modus operandi e status especiais para tratados que versem sobre Direitos Humanos.

A Carta Magna brasileira, ao prover caráter especial aos tratados sobre Direito Humanos, minimiza a problemática da ordem internacional, incorporando ao ordenamento pátrio não apenas o tratado em si, mas também o caráter universalista e, por que não, cosmopolita que permeia o Sistema ONU.

\section{Referências}

ALVES, José Augusto Lindgren. Relações internacionais e temas sociais: a década das conferências. Brasília: Funag/ IBRI, 2001.

ARAUJO, Cícero. Bentham: el utilitarismo y la filosofía política moderna. In: BORON, Atilio A. (Org.). La filosofía política moderna. Buenos Aires: Editorial Universitaria de Buenos Aires, 2000. p. 269-288. Disponível em: <http:// blocs.xtec.cat/filocostaillobera/files/2008/04/assaigsobre-bentham.pdf>. Acesso em: 29 maio 2014 .

BOBBIO, Norberto. A era dos direitos. Tradução: Carlos Nelson Coutinho. Rio de Janeiro: Elsevier, 2004.

BRASIL. Constituição (1988). Emenda Constitucional $n^{\circ}$ 45, de 30 de dezembro de 2004.

BULL, Hedley. A sociedade anárquica: um estudo da ordem na política mundial. Tradução: Sergio Bath. Brasília: UnB; São Paulo: IPRI/Imprensa Oficial de São Paulo, 2002.

HOMEM, António P. Barbas. História das relações internacionais: o direito e as concepções políticas na idade moderna. Lisboa: Almedina, 2010.

KANT, Immanuel. A paz perpétua: um projecto filosófico. Tradução: Artur Morão. Covilhã: Lusofonia Press, 2008. Disponível em: <http://www.lusosofia.net/textos/kant_ immanuel_paz_perpetua.pdf $>$. Acesso em: 29 set. 2013.

MAZZUOLI, Valerio de Oliveira. Direitos humanos, Constituição e os tratados internacionais: estudo analítico da situação e aplicação do tratado na ordem jurídica brasileira. São Paulo: J. de Oliveira, 2001. 
MAZZUOLI, Valerio de Oliveira. O treaty-making power na Constituição brasileira de 1988: uma análise comparativa do poder de celebrar tratados à luz da dinâmica das relações internacionais. Revista Brasileira de Política Internacional, Brasília, v. 44, n. 2, p. 82-108, 2001.

MELLO, Celso de. Carta Rogatória n 8.279-República Argentina. Informativo STF, n. 109, Brasília, 4 a 8 de maio de 1998. Disponível em: <http://www.stf.jus.br/arquivo/ informativo/documento/informativo109.htm $>$. Acesso em: 22 maio 2014

MENDES, Gilmar F.; BRANCO, Paulo G. G. Curso de direito constitucional. 9. ed. São Paulo: Saraiva, 2014.

ORGANIZAÇÃO DAS NAÇÕES UNIDAS. Declaração e Programa de Ação de Viena: Conferência Mundial sobre Direitos Humanos. Viena: ONU, 1993. Disponível em: <http://www.dhnet.org.br/direitos/anthist/viena/viena. html>. Acesso em: 19 mar. 2016.

PIOVESAN, Flávia. Direitos humanos e o direito constitucional internacional. 8. ed. São Paulo: Saraiva, 2007.
PORTELA, Paulo Henrique Gonçalves. Direito internacional público e privado. 2. ed. Salvador: JusPodivm, 2010.

REZEK, Francisco. Direito internacional público: curso elementar. 14. ed. São Paulo: Saraiva, 2013.

TAVARES, André Ramos. Curso de direito constitucional. 7. ed. São Paulo: Saraiva, 2009.

UNITED NATIONS TREATY COLLECTION. Chapter XXIII law oftreaties. 2014. Disponível em: $<$ https://treaties. un.org/Pages/ViewDetails.aspx?src=TREATY\&mtdsg no $=$ XXIII-3\&chapter $=23 \&$ lang $=\mathrm{en}>$. Acesso em: 14 maio 2014.

WATSON, Adam. A evolução da sociedade internacional: uma análise histórica comparativa. Tradução: René Loncan. Brasília: UnB, 2004.

WIGHT, Martin. A política do poder. 2. ed. Tradução: Carlos Sérgio Duarte. Brasília: UnB; São Paulo: IPRI; Imprensa Oficial de São Paulo, 2002. (Clássicos IPRI, 7).

ZAVERUCHA, Jorge. FHC, Forças Armadas e polícia: entre o autoritarismo e a democracia. Rio de Janeiro: Record, 2005. 